\title{
Effects of Neurofeedback on Memory of Migraine Patient
}

\section{Elham Asbaghi* and Mahdieh Rahmanian}

Clinical Psycology, University of Mohaghegh Ardabili, Iran

\begin{abstract}
Introduction: Migraine is sever and painful type of headache which can be treated in different ways. Recent studies have demonstrated that neurofeedback is a good option for treatment of migraine headaches.

Method: The main aim of present research was to investigate the effect of neurofeedback on Memory of migraine patients. To do so, a sample of 30 subjects was selected for experimental and control groups by a accessible sampling procedure. Subjects were assessed with the Wechsler Memory Scale in two stages (pretest and posttest). The obtained data were analyzed through covariance analysis method.

Result: After 30 sessions of neurofeedback training, considerable improvement in general memory of the experimental group was observed. Also the two groups (experimental and placebo) presented significant differences in the memory.

Conclusion: According to the researcher's view, migraine patients are able to control their brainwaves with participating in neurofeedback training sessions, so their total memory would be increased.
\end{abstract}

Keywords: Neurofeedback; Migraine patients; Memory

\section{Introduction}

Migraine is a common, disabling and often progressive disorder characterized by increased excitability of the central nervous system $[1,2]$. It occurs in $18 \%$ of women and $6 \%$ of men in the US with peak prevalence in individuals between the ages of 25 and 55 [3]. Economic burden of migraine in the US is estimated to be approximately 13 billion annually [4].

Memory is non-separable component on individuals cognitive system [5]. It is a process that knowledge will be coded, reserved, and remembered. In addition, many of important behaviors are learned. Our personal values depends on what we have learned and what we will remember [6]. Memory is able to maintain information within an internal researchable keeping system, as this information is accessible and usable. In the recent decades, understanding natural and disturbed memory has been developed more than other cognitive features [7]. All of our learning, thinking, planning and social behaviors are shaped base on our memory. Human being's memory is as equal as his senses. Recognition of smells (smell memory), sounds (hearing memory), tastes (tasting memory), colors (observing memory), and roughness and smoothness (touch memory) require their recollection in memory. Human beings cannot make relationship with others, execute their tribal customs, represent their senses, recognize face of their friends and even knows the way to their home.

Memory would be influenced by many factors, including multilanguage, intelligence, and mental health [7]. Therefore, methods and techniques which are able to improve memory are very important. Among these, Neurofeedback Training (NFT) is a state of art training based on operant conditioning. It requires an individual to modify the amplitude, frequency or coherence of the electrical activity and learn to influence the electrical activity of their brain. The goal is to train the individual to normalize abnormal EEG frequencies, Decreasing Theta and increasing sensory motor rhythm (SMR) activity $(10-13 \mathrm{~Hz})$ lead to improve cognitive performance [8].

Generally, in neurofeedback training sessions, person will be familiar with his/her different situations of brain waves, and he/she can control them. In fact, neurofeedback is based on implicit and nonconscious learning and conditioning $[9,10]$.

Vernonet et al. [11] concluded that neurofeedback has positive effect on some dimensions of cognitive performance, including precision at work memory. In another study, Gholizade [12] evaluated effect of neurofeedback training on observing memory of students. In the study 30 students learned to control their brain waves voluntarily and increased memory performance by it.

\section{Method}

This is an experimental study with pre-posttest plan with control group. In this study, Neurofeedback training is considered as independent variable, and memory as dependent variable.

The sample of present research contains 30 migraine patients who selected by accessible sampling. 15 subjects were allocated to neurofeedback (experimental) group and 15 participates were allocated to control group. The range of samples' age was 22-51 years old with average 34.06 and standard deviation 8.07 . The number of male and female participates were 17 and 23, respectively. The obtained data were analyzed through covariance analysis method with spss version 17 .

\section{Instruments}

\section{Neurofeedback amplifier}

Neurofeedback amplifier is a device which analyzes the received raw brain waves through located electrodes on the head to frequencies of different waves. These frequencies are delta, theta, alpha, and beta

*Corresponding author: Elham Asbaghi, MA in Clinical Psycology, University of Mohaghegh Ardabili, Iran, Tel: 09125492865; E-mail: elham.asbaghi.1988@gmail.com

Received August 07, 2012; Accepted October 03, 2012; Published October 05, 2012

Citation: Asbaghi E, Rahmanian M (2012) Effects of Neurofeedback on Memory of Migraine Patient. J Neurol Neurophysiol 3:138. doi:10.4172/2155-9562.1000138

Copyright: @ 2012 Asbaghi E, et al. This is an open-access article distributed under the terms of the Creative Commons Attribution License, which permits unrestricted use, distribution, and reproduction in any medium, provided the original author and source are credited. 
waves. During neurofeedback training electrodes are located on scalp according to 20-10 international system. Patient is requested to seat in front of computer and control the video games which are showing in screen, by concentration on computer screen. The games go on by decreasing inappropriate wave activity and increasing appropriate wave activity. In the beginning, brain waves' changes are temporal but permanent changes will be gradually occurred by repeating sessions [13].

In this study researchers used a neurofeedback device, made by Thought Technology Ltd. that called ProComp2". The ProComp2" is a 2 channel device that contains a built-in EEG sensor (simply connect an extender cable for EEG monitoring and biofeedback). The ProComp2" system contains all the peripherals to easily connect it to a desktop or laptop IBM-compatible PC.

\section{Wechsler memory scale (WMS-IV) for adult}

This scale has been designed for memory assessment as an objective measure and it is based on several years research and survey about functional simple and immediate memory and provide information for separation action disorders of memory. Wechsler memory scale (form A) Contain 7 Subscale including information and orientation mental control, logic memory, Digit Span, Verbal Paired Associates, and Visual Reproduction. Shokri et al. [14] evaluated Cronbach's alpha coefficient for Wechsler memory subscales. The results showed 0.96, $0.93,0.69,0.89,0.77,0.83$ and 0.81 for information and orientation mental control, logic memory, Digit Span, Verbal Paired Associates, and Visual Reproduction, respectively.

\section{Procedure}

For each subject 30 neurofeedback training sessions was held and each session lasted 45 minutes. The experimental group received feedback based on their performance, in contrast control group's feedback was not based on their performance (in fact their sessions weren't neurofeedback training and they didn't know that they conducted placebo training). In the first session, before neurofeedback training, memory test were performed on all subjects, individually. Then neurofeedback training was carried out for experimental group according to this protocol: increasing SMR wave $(12-15 \mathrm{~Hz})$ and decreasing high beta $(19-32 \mathrm{~Hz})$ and Theta $(4-8 \mathrm{~Hz})$ in $\mathrm{Cz}$ area.

\section{Date Analyses}

Data were analyzed using SPSS (Statistical Packages for the Social Sciences) PC version 17 for Windows. All differences were considered significant if the probability of error was $\mathrm{p}<0.05$. To compare memory scores between groups multivariate analysis of variance (MANOVA) was used.

\section{Result}

To evaluate mean and standard deviation of subjects' memory scores in pre and post test descriptive analysis was used. The results have been demonstrated in table 1 .

As has been shown in table 1 , the memory scores mean of experiment group in pre and post test were 68.30 and 77.30, respectively. In addition, the results showed that the control subjects' mean of memory scores were 72.8 and 75.33 , respectively.

In the present study in order to compare differences between migraine patients and control groups on memory scores, the individual's scores on Wechsler memory scale and its subscales in post test stage were evaluated as multivariate analysis (MANOVA). The MANOVA's results have been given in table 2 .

As have been shown in table 2, MANOVA revealed significant differences between experimental and control groups on total memory score $\mathrm{F}(1,28)=26.88, \mathrm{p}<0.000$. In addition, the results showed that some subscale scores were significantly different between two groups, such as mental control F $(1,28)=16.66$, p $<0.001$, Digit Span F $(1,28)$ $=20.86, \mathrm{p}<0.001$, Verbal Paired Associates $\mathrm{F}(1,28)=4.53, \mathrm{p}<0.05$, Visual Reproduction F $(1,28)=33.55, \mathrm{p}<0.001$. Significant differences between groups reflected that migraine subjects had greater scores on memory scale than control participates after neurofeedback training.

On the other hand, as have been shown in table 2, the findings indicated that the two groups differences on logic memory was found to be non-significant, $\mathrm{F}(1,28)=0.49$, NS, that reflected neurofeedback training didn't influenced logic memory of migraine patients.

\section{Discussion}

The main aim of the present study was to investigate the effect of neurofeedback training on Memory of migraine patients. The results showed that neorofeedback training improved memory of these subjects. several studies provided research's result [15-20] In fact, neurofeedback is a mechanism for repair and reconstruction of brain waves. Patients could improve their wave's pattern by continuous training, feedback and practice. It is a practice for brain and so with this training session the memory will be increased and the changes will become permanent gradually. There are evidences during recent 25 years, which show this learning phenomenon would be influenced by unconscious processes and person can learn without direct awareness [21]. As neurofeedback is based on learning and conditioning process (especially deals whit brain conditioning), its effect occurs after about 30 sessions [22]. The protocol which used in present study was to increasing SMR wave on $\mathrm{Cz}$ area (Sensory motor cortex and cingulate cortexes). Also, the patient who has difficulty in understanding logical

\begin{tabular}{|c|c|c|c|c|c|c|c|c|}
\hline \multirow[b]{2}{*}{ Variable } & \multicolumn{2}{|c|}{ Post -test of control group } & \multicolumn{2}{|c|}{ Pre -test of control group } & \multicolumn{2}{|c|}{$\begin{array}{l}\text { Post-test of experimental } \\
\text { group }\end{array}$} & \multicolumn{2}{|c|}{$\begin{array}{c}\text { Post -test of experimental } \\
\text { group }\end{array}$} \\
\hline & Standard deviation & Mean & Standard deviation & Mean & $\begin{array}{l}\text { Standard } \\
\text { deviation }\end{array}$ & Mean & $\begin{array}{l}\text { Standard } \\
\text { deviation }\end{array}$ & Mean \\
\hline Information & 0 & 6 & 0 & 6 & 0 & 6 & 0 & 6 \\
\hline Orientation & 0 & 5 & 0 & 5 & 0 & 5 & 0 & 5 \\
\hline Mental control & 1.6 & 7.73 & 1.3 & 7.8 & 0.457 & 8.73 & 0.67 & 7.8 \\
\hline logic memory & 3.8 & 13.9 & 4.1 & 12.7 & 3.7 & 15.1 & 4.14 & 13.06 \\
\hline Digit Span & 3.58 & 12.5 & 4.6 & 12.8 & 0.83 & 9.7 & 1.2 & 8.3 \\
\hline Verbal Paired Associates, & 2.5 & 17.7 & 2.17 & 17.03 & 1.3 & 19.76 & 1.37 & 18.23 \\
\hline Visual Reproduction & 7.06 & 75.33 & 5.98 & 72.8 & 4.48 & 77.10 & 5.15 & 10.93 \\
\hline Total & 7.06 & 75.33 & 5.98 & 72.8 & 4.48 & 77.10 & 5.15 & 68.30 \\
\hline
\end{tabular}

Table 1: Mean and standard deviation of memory scores in pre- and post test. 


\begin{tabular}{|c|c|c|c|c|}
\hline & & Df & $\mathbf{F}$ & $\mathbf{P}$ \\
\hline \multirow[t]{6}{*}{ Model } & Mental control & 1 & 0.463 & 0.502 \\
\hline & logic memory & 1 & 8.53 & 0.007 \\
\hline & Digit Span & 1 & 8.62 & 0.000 \\
\hline & Verbal Paired & 1 & 36.36 & 0.000 \\
\hline & Visual Reproduction & 1 & 182.68 & 0.000 \\
\hline & Total & 1 & 84.79 & 0.000 \\
\hline \multirow[t]{6}{*}{ Group } & Mental control & 1 & 16.66 & 0.000 \\
\hline & logic memory & 1 & 0.492 & 0.492 \\
\hline & Digit Span & 1 & 20.86 & 0.000 \\
\hline & Verbal Paired & 1 & 4.530 & 0.042 \\
\hline & Visual Reproduction & 1 & 33.554 & 0.000 \\
\hline & Total & 1 & 26.88 & 0.000 \\
\hline \multirow[t]{6}{*}{ Error } & Mental control & 28 & & \\
\hline & logic memory & 28 & & \\
\hline & Digit Span & 28 & & \\
\hline & Verbal Paired & 28 & & \\
\hline & Visual Reproduction & 28 & & \\
\hline & Total & 28 & & \\
\hline
\end{tabular}

Table 2: TLUSER AVONA.

continuity of cognitive function can use neurofeedback training on sensory motor cortex in left hemisphere (C3) and training on sensory motor cortex in right hemisphere (C4) could facilitate mixed answer. Cingulated system deals with excitement feeling, attention and working memory. So, increasing sensory-motor rhythm decrease unrelated motives and facilitates integrity of motives related to performance [23] and consequently, effects on conceptual memory directly [24]. In addition, in the study theta was inhibited on $\mathrm{Cz}$ area. Theta wave is related to confusion, inattention, imagination, depression and anxiety [25]. Therefore, it seems all researchers agree with this idea that increasing activity of slow theta is causing the problem and it could be solved by neurofeedback training [23].

It is known from previous research that theta activity has an influence on the cellular mechanisms of memory through its role in facilitating long-term potentiation [26], and more recent studies have documented a link between recognition memory processes and theta activity recorded from the scalp [27]. Convincing evidence of the direct relationship between theta and working memory stems from data showing that, during the encoding phase of a recognition task, only words that were later correctly recognized exhibited a significant increase in theta activity [28]. In addition, during the later recognition phase, greater theta activity was found for correctly recognized words but not distracters. Based on research showing that working memory utilises the posterior association cortex, involved in the storage of sensory information, and the pre-frontal cortex which updates the information [29-31] one proposal is that theta activity links these two regions together during memory task [32].

\section{References}

1. Lipton RB, Bigal ME (2005) Migraine: epidemiology, impact, and risk factors for progression. Headache 45: S3-S13.

2. Ambrosini A, de Noordhout AM, Sándor PS, Schoenen J (2003) Electrophysiological studies in migraine: a comprehensive review of their interest and limitations. Cephalalgia 1: 13-31.

3. Lipton RB, Bigal ME, Diamond M, Freitag F, Reed ML, et al. (2007) Migraine prevalence, disease burden, and the need for preventive therapy. Neurology 68: 343-349.

4. Hu XH, Markson LE, Lipton RB, Stewart WF, Berger ML (1999) Burden of migraine in the United States: disability and economic costs. Arch Intern Med 159: 813-818.
5. Haritos C (2002) A developmental examination of memory strategies in bilingual education and bilingualism 5- 197-220.

6. Kandel RE, James HS, Thomas MJ (2000) Principles of Neural Science .McGraw-Hill Compaines.

7. Ghanaii A (2008) Effect of sport rhythmic movement training on memories neuropsychological function in student with learning disabilities [dissertation] Tabriz:Tabriz university.

8. Rasey H, Lubar JF, Mc Intryre A, Zuffuto A, Abbote PL (1996) EEG biofeedback for the enhancement of attentional processing in normal collge students. Journal of Neurofeedback 1: 15-21.

9. Vernon D, Frick A, Gruzelier JH (2004). Neurofeedback as a treatment for ADHD: a methodological review with implications for future research. Journal Neurotherapy 8: 53-82.

10. Barzegar L, Yaghubi H (2009) Effect of Neurofeedback Therapy on OCD, Tabriz University 23: 23-43.

11. Vernon D, Egner T, Cooper N, Compton T, Neilands C, et al. (2003) The effect of training distinct neurofeedback protocols on aspects of cognitive performance. Int J Psychophysiol 47: 75-85.

12. Gholizade Z, Babapuor KH, Rostami R, Beirami M Poursharifi H (2010). Effect of Neurofeedback on Visual Memory. Behavior Science: 285-289. [persian]

13. Demos NJ (2005). Getting Started with Neurofeedback .W. W. Norton\& Company. New York.

14. Shokri O, Farahani MN, Farzad V, Safaei P, Sangari AA (2008). factoria validity and reliability of farsi version of the student life stress inventory. Rese Pscho Heal 2: 17-27. [persian]

15. Bri'ere M, Forest G, Lussier I, Godbout R (2000). Implicit verbal recall correlates positively with EEG sleep spindle activity

16. Schiffelholz T, Aldenhoff JB (2002) Novel object presentation affects sleepwake behavior in rats. Neurosci Lett 328: 41-44.

17. Schabus M, Gruber G, Parapatics S, Sauter C, Klosch G, et al. (2004). Sleep spindles and their significance for declarative memory consolidation. Sleep 27 1479-1485.

18. Clemes Z, Fabo D, Halasz P (2005). Overnight verbal memory retention correlates with the number of sleep spindles. Neuroscience 132: 529-535.

19. Schabus M, Hödlmoser K, Gruber G, Sauter C, Anderer P, et al. (2006) Sleep spindle-related activity in the human EEG and its relation to general cognitive and learning abilities. Eur J Neurosci 23: 1738-1746.

20. Berner I, Schabus M, Wienerroither T, Klimesch W (2006) The significance of sigma neurofeedback training on sleep spindles and aspects of declarative memory. Appl Psychophysiol Biofeedback 31: 97-114.

21. Barzegar L, Yaghubi H(2009). Effect of Neurofeedback Therapy on OCD, Tabriz University 23: 23-43.

22. Hammond DC (2006). What is Neurofeedback? University of School Medicine ECNS, QEEG-D, BCIA-EEG,1-9.

23. Gruzelier J, Egner T (2005) Critical validation studies of neurofeedback. Child Adolesc Psychiatr Clin N Am 14: 83-104.

24. Vernon D, Frick A, Gruzelier $\mathrm{JH}(2004)$. Neurofeedback as a treatment for ADHD: a methodological review with implications for future research. Journal Neurotherapy 8: 53-82

25. Blume WT and kaibara M(1995) Atlas of adult electroencephalography . New York:Raven Press

26. Poe GR, Nitz DA, McNaughton BL, Barnes CA (2000) Experience-dependent phase-reversal of hippocampal neuron firing during REM sleep. Brain Res 855 176-180.

27. Burgess AP, Gruzelier JH (1997) Short duration synchronization of human theta rhythm during recognition memory. Neuroreport 8: 1039-1042.

28. Klimesch W, Doppelmayr M, Schimke H, Ripper B (1997) Theta synchronization and alpha desynchronization in a memory task. Psychophysiology 34: 169-176.

29. Gevins A, Smith ME, McEvoy L, Yu D (1997) High-resolution EEG mapping of cortical activation related to working memory: effects of task difficulty, type of processing, and practice. Cereb Cortex 7: 374-385. 
Citation: Asbaghi E, Rahmanian M (2012) Effects of Neurofeedback on Memory of Migraine Patient. J Neurol Neurophysiol 3:138. doi:10.4172/21559562.1000138

Page 4 of 4

30. Goldman-Rakic PS (1988) Topography of cognition: parallel distributed networks in primate association cortex. Annu Rev Neurosci 11: 137-156.

31. Klimesch W, Schimke H, Schwaiger J (1994) Episodic and semantic memory: an analysis in the EEG theta and alpha band. Electroencephalogr Clin Neurophysiol 91: 428-441.
32. Sarnthein J, Petsche H, Rappelsberger P, Shaw GL, von Stein A (1998) Synchronization between prefrontal and posterior association cortex during human working memory. Proc Natl Acad Sci U S A 95: 7092-7096. 